\title{
On Strategies of Using Picture Books to Dredge Children's Negative Emotions
}

\author{
Huiyu Guo \\ Middle Campus, Xi'an University, No.212, South Taibai Road, Xi'an, Shaanxi Province \\ 263279298@qq.com; ghuiyu72@126.com
}

Keywords: Picture book; Negative emotions

\begin{abstract}
Childhood is an important period in which an individual gains and develops the understanding and expression of negative emotions. If the children's emotions are not well developed at this time, their subsequent personality and character development will be greatly affected, leading to serious psychological problems. This paper explores the methods to dredge children's negative emotions, i.e., carrying out parent-child reading, and carrying out emotional education activities in kindergartens using picture books as a carrier, and focusing on children's emotions in a way of home-school communion.
\end{abstract}

\section{Introduction}

The "emotional health and pleasure" goal is proposed in the field of health in "Guide for the Learning and Development of Children Aged 3-6", and it is proposed in educational suggestions to help infants express and control their emotions in an appropriate way; allow infants to express their emotions and guide them properly; take the initiative to ask infants when they are found to be in low ebb so as to help the resolve negative emotions. ${ }^{[1]}$

Childhood is an important period for children to acquire and develop the understanding and expression of negative emotions. According to child psychology researchers, emotional experience before the age of 6 has a lasting impact on the future development of personality. If children have excessive emotional ups and downs during this period, they are unable to concentrate and are prone to violence and anger. Personality problems such as being prone to temper, low self-esteem, or being alone, anxious, dissatisfied with oneself, etc., have a greater influence on the character formation and character development of young children. If negative emotions often appear and cannot be vented, it will have a lasting negative impact on the child's positive emotions, which will affect the child's physical and mental health and the good development of peer relationships. The existence of emotions is very common, but people basically lack the necessary understanding and attention, thinking that even if they are negative emotions, it doesn't matter. They will disappear after a while, but it's not true. The long-term accumulation of negative emotions will greatly harm people's physical and mental health. ${ }^{[2]}$ It is because of the negative influence of children's negative emotions that it is particularly important to dredge children's negative emotions and help children learn to manage their own emotions. Through emotion management education, children must not only learn to express their various emotions such as happiness, sadness, fear, fear, and tension, but also finally learn to perceive and regulate their own negative emotions, so that positive and happy emotions will accompany children's growth and lives.

The development of children's psychological mechanisms is not perfect. They have no way to regulate their emotions like adults, and vent their emotions in the right way. At this time, adults need to help them ease negative emotions. The author has found through investigation that $80 \%$ teachers believe that dull teaching does not apply to children and may even make children psychologically bored and become less receptive to adults' persuasion. The fact that adults' physical and mental development characteristics are not taken into account when adults are preaching is an important reason for this result. If adults show picture books to young children, using their graphic and artistic features, it can effectively guide their negative emotions.

The reading of a picture book is a pleasant and enjoyable process that regulates children's 
psychological and physical health in a relaxed and pleasant atmosphere. Children's emotions cannot be vented at any time because of time and place. Through reading, they can promptly release children's negative emotions, so that children can easily and freely express their emotions that are occasionally repressed. Picture books help children understand their own and others' ideas and behaviors. While reading the picture book, children are actually understanding the thoughts and behaviors of the protagonist in the book, which paves the way for children to understand others in reality. Each picture book will involve some problems. In the whole process of reading, children are actually in the process of continuously solving problems, providing children with multiple perspectives and methods to think about and solve problems. The storyline in the picture book is sometimes experienced by children personally. It is easy for children to release their emotions while generating emotional resonance with the protagonist in the book.

The high-quality illustrations and language in the picture books have an unpredictable and subtle influence on the cultivation of children's cognitive ability in all aspects. In the picture book, the artist designs and hides many hard-to-find details, such as ring linings, to stimulate children's interest in reading and to exercise children's observation skills. When guiding children to read picture books, we can throw out some open questions so that children can fully exert their imagination. Throughout the reading and communication process, children have learned not only the true meaning of life, but also the development of multi-faceted abilities such as thinking ability, observation, attention, imagination, and so on. ${ }^{[3]}$

Among the many picture books, there is a series of "emotional themes" specifically designed for children's emotions. Among them, there is a very delicate and in-depth discussion of children's various emotional problems with children's tone, standing in the children's position to tell the story, so that children can be well integrated into the story, engage in emotional communication with the protagonist, and projected into their own real life to better understand the emotional and emotional changes of themselves and others. ${ }^{[4]}$ When a child encounters emotional problems and we cannot communicate with him, let him communicate with the picture book. For example, the book "Sophie Gets Angry" focuses on the state of anger and the catharsis process. Through this story, you can let young children see how Sophie was angry when she did it and what ways she used to vent her negative emotions. ${ }^{[5]}$ The whole process is based on guidance, so that young children can stand in the position of Sophie to experience emotional changes. Then when he encounters a similar situation in real life, he will subconsciously imitate the protagonist's method in the story to solve the problem. ${ }^{[3]}$

In practice, the author explores the following strategies for dredging children's negative emotions through picture books.

\section{Parent-child Co-reading is a Parent-child Activity in which Parents Communicate with Children}

Parents and children read the picture book. In the warm and loving place of the family, parents and children engage in spiritual communication. The story in the book is heard in the voice of the parents, allowing children to learn and develop their abilities and feel love. ${ }^{[6]}$ The words of parents, especially warm and emotional language, can promote the healthy development of children's minds. The companionship of parents is beneficial to the elimination of children's negative emotions, and the unique charm of picture books will have a positive effect on children's positive emotional and emotional experience, which will help improve children's emotional regulation and management capabilities. When reading books with children, parents should pay attention to:

Select the suitable picture books. Nowadays, people pay more and more attention to early childhood education, and young children are getting younger and younger when they begin to read picture books. We can't blindly read. We must choose the picture book that suits our child according to the characteristics and ability of each age group of the child. In this regard, Mr. Tadashi Matsui; pointed out: "For the enlightening picture books that are suitable for babies, the illustrations must be accurate and true. There is no need for too much background and detailed description, that is, a picture book depicting real things." "About two years old children are suitable for reading "life 
experience picture books' related to their daily life experience, followed by 'cognitive picture books' that introduce basic cognitive knowledge, and these children can also choose simple children's songs, poetry, or vivid words, cheerful rhythm picture book". "The vocabulary of children aged 3-5 and 6 is rapid development. Their imagination and curiosity are also increasing rapidly. They can quickly integrate into the stories. Presenting picture books to them not only improves children's reading skills, and to a certain extent, has cultivated the children's good reading habits in the future";

Read the picture book in advance. Mr. Tadashi Matsui wrote in his book that: "No matter how vivid the picture books are, if the readers are perfunctory, they cannot vividly express the content of the story.". Therefore, parents should read the picture book before they are going to tell the children stories, dig out the deep meaning of the picture book and the reasoning to be explained, and read it with the children after preparing.

Read with emotions and feelings. Will the picture book be bought for children to read by themselves or by parents and children? In terms of this, Mr. Tadashi Matsui unconditionally supported the latter. He repeatedly emphasized that the picture book is the most suitable and should be read by parents to children. If parents want to read and write picture books for children, the speed of speech must be slowed down, and the pronunciation should be clear. It is better to read the characters in different roles, read out the voices and tones of different characters, and boldly imitate various small animals. Expressions and body movements should be exaggerated as much as possible, which can better attract children's attention.

Allow children to participate in. Continuously interact with children during the reading process. When reading a picture book with multiple characters, you can perform role-playing with your child and improve your child's participation.

What are the best picture books? When parents choose picture books for their children, they always want to choose the best for them. Then what is a good picture book and how to discern the quality of the picture book? Mr. Tadashi Matsui suggests that: With more exposure to picture books and more excellent picture books and illustrations, slowly you will have the ability to judge the quality of the picture book. Whenever you come into contact with a new picture book, this intuition will come into play. Compare with picture books so that you read before and give judgments.

Encourage children to boldly express their viewpoints. The child's thinking sometimes jumps, so for some of the child's views, don't limit it if we think it's wrong. Children's imagination and creativity are far from what we adults can foresee. What our parents need to do is to encourage their children more than to criticize children because they do not say what we call "standard answers." Some guiding questions may be appropriately presented, but the degree of difficulty of the question is based on the child's ability to accept, and not too much, so as not to burden the child with reading. Keeping abreast of your child's parent-child reading is based on a relaxed and pleasing atmosphere. While allowing children to enjoy the nourishment and happiness of love, they can learn some knowledge and life principles.

Allow children to love a book. One of the characteristics of reading and listening to children in early childhood is the repetition. We will find that even if the story has already been told, the children will also ask for a repeat. Faced with this situation, some parents would agree with the child's request, and some parents choose to reject the child to simply pursue the number of children to read, and recommend another picture book for the child. Mr. Tadashi Matsui's proposal was to allow children to read the same picture book repeatedly, and not to impose another one on the child. Children like to read the same picture book is also the same, holding his favorite picture book, I believe that children will have different discoveries and emotional experience each time. ${ }^{[8]}$

\section{Use Emotional Picture Books' Intuitive Cover to Evoke Children's Interest in Reading and Lay the Emotional Foundation}

In a good picture book, every detail is not superfluous. It is the source of the entire story information. Whether it is the front cover, back cover, ring lining, or front page is an important part of the entire story, it may also conceal the entire story clue. ${ }^{[9]}$ Peng Yu, a researcher of children's 
literature, wrote in The Picture Book Should Read: "The excellent cover is the content of a picture book. It will immediately attract our attention, and we cannot but create a kind of wish to take it in hand and have the urge to read carefully". Especially for the emotional picture books, and from some of the cover illustrations we can directly read the protagonist 's emotions, but cannot directly read why the protagonist will produce such emotions. For example, we can see directly from the cover of the book "Sophie Gets Angry": When a little girl's hair rises and she has big eyes, it is easy to think that she may be angry. Then we may wonder why she gets angry. This sets a suspense for young children to a great extent, causing the children's interest in reading and making them want to explore the protagonists' emotions.

Therefore, the first step in reading the picture book is to read the cover. In the actual education and teaching activities, the teacher can guide the children to carefully observe the cover of the picture book. In particular, guide children to carefully observe the cover display environment, the color of the cover, and people or animals. The details of appearance, movement, and demeanor can be quickly brought into the emotional world of the protagonist in the picture book story. At this time, the young children began to boldly associate and speculate about the protagonist's experiences and the causes that may cause the protagonist's emotions. With the hope of continuing to read the picture books, their interest in reading is more effectively arisen. In order to allow children to further in-depth reading of the picture book with their own speculations, and to deepen the foundation for the emotional perception and experience of the picture book story, it also laid the emotional state of the child from the very beginning and fully exerted the emotional motivation. ${ }^{[7]}$

\section{Use Rich Illustrations to Guide Children to Read Pictures and Get Story Information}

The picture book is a good intermediary to guide children to learn emotional knowledge, feel emotional changes, and solve emotional problems. In the emotional picture book, the expression of a certain kind of emotion is expressed by the specific image details. For example, the picture of the book "I am sorry" in the mood book is printed with a picture of "The little guinea pig who missed a man but he was very sad when he was not there." This conveys the sadness of the protagonist Xiao Tian Zuo. From this it can be seen that the picture plays a distinctive role in the emotional picture book. It not only conveys and expresses some kind of emotional knowledge, but also hides the background factors that cause the protagonist to produce a certain emotion, environment, etc. Pictures directly reveal when the protagonist of the story produces a negative emotion, the protagonist's corresponding emotional behavior and specific adjustments. This not only provides children with experience and understanding of emotional knowledge, but also lays a foundation for children to transform their emotional knowledge into their own behavior.

According to the child's physical and mental development characteristics, when children have limited knowledge of the text, almost all attention is drawn to the picture. They obtain story information. Therefore, when teachers guide young children to read emotional picture books, they should have the purpose to guide children to carefully read pictures, observe the various emotional theme elements contained in each picture, and on this basis, provide explanations, analysis, and sum up related emotional knowledge for children. Specifically, guiding children to read pictures mainly includes guiding children to follow the following elements in the picture book illustration:

Observe the emotions of the protagonist of the story and define the types of emotions, such as sadness, sorrow, fear, nervousness, etc., so as to understand relevant emotional knowledge;

Get the external causes that lead to the emotions of the protagonist of the story;

Observe and preliminarily summarize the main causes of the protagonist's emotions;

Observe the protagonist's emotional behaviors and changes in emotions as he goes through different things;

Observe the protagonist's specific measures in the face of negative emotions, and compare the difference between the protagonist's emotional performance before and after adjustment for negative emotions. 


\section{Combine Texts and Pictures in Reading to Arouse the Infants' Emotional Resonance with the Story Protagonist}

Picture books' feature of combing pictures with texts will inevitably be reflected in the process of guiding infants to read. When children read picture books, each picture will be subconsciously interpreted with their own life experience. As each child's life experience is not the same, there may be several different interpretations of a picture. There is certainly an unreasonable interpretation of a reasonable interpretation. This requires our teachers to help young children read pictures and texts on the basis of guiding children to read pictures alone, thereby helping young children to correctly understand each emotional knowledge in the emotional picture book, accurately grasping the development and change process of each emotion, and consolidating children's emotional experience. The point to be explained here is that even under the guidance of teachers, children may have different views on the causes, events, and results of some emotions in the process of reading pictures, and there is a phenomenon of "multiple meanings in one picture". At this time, the necessary discussion can be conducted to obtain the final result, thereby deepening the children's impression of the three factors: the cause of emotion, the process of emotional regulation, and the result of emotional regulation. The combination of pictures and text in reading mainly focuses on the guidance of teachers. It is mainly teachers' unreasonable understanding of young children. On the basis of the author's writing, they help young children correctly understand the content expressed in each picture and convey the correct emotional knowledge. .

\section{Use Teacher-Infant Interaction and Discussion to Complete Emotional Experience}

When teachers and children read the emotional picture book together, whether teachers or young children have different experiences because of different emotions, they will have different experiences and feelings, and they will have different ways of expression. For example, when teachers are angry, they may choose to keep silent, and young children may cry or throw things. There will also be different ways of venting. Some educators put forward that when teaching picture books, and the first and most important thing is to create a warm, free and open natural environment for young children. Therefore, in reading emotional picture books, teachers should mobilize the enthusiasm of young children to participate in the discussion and interaction, encourage children to boldly express their own ideas, guide children through the discussion step by step to associate, think, express, help children to complete a series of psychological activities combined with existing experience and emotional experience.

The interaction and discussion between teachers and students can be specifically carried out from the following three aspects:

The first is the discussion of the content of the story. This kind of discussion is the most basic part of the entire interactive discussion process. The main purpose is to help the children sort out the story and understand the protagonist's emotional problems, solutions, solutions, and related emotional changes. The interaction and discussion in this area mainly focuses on the content of the story itself. The questions that can be discussed are: Who is the protagonist of the picture book story? What good or bad things the protagonist has encountered? How do these things make the story protagonist feel? What kinds of negative emotions (heartache, fear, anger, etc.) have the story protagonists had? When the protagonist of the story feels angry (scared, sad), how does he deal with these negative emotions? When the story owner used various methods to ease negative emotions, what kind of changes did his mind make?

The second is to discuss children's life experience. This kind of interaction is mainly discussed through the experiences of young children's life and the similarities of the emotional story protagonists in the picture books. The purpose is to guide young children to actively connect the stories in the picture book story with their own life experiences, and to read the basics of the picture book story. Evoke children's related life experience. The interaction and discussion in this area 
mainly focuses on the combination of children's experiences and stories. The questions that can be discussed are: When the story protagonist has a certain mood, how does the other animal or character in the story feel? After reading the protagonist's story, what kind of feeling do you have? how do you feel? If you are the protagonist of the story, how would you alleviate, vent, and solve the negative emotions you encountered? Have you ever had the same feeling or experience as the protagonist of the story?

The third is about guiding young children to apply the learned knowledge and experience to practical discussions. The ultimate goal of this interactive discussion is to guide young children to apply the methods of dealing with negative emotions learned in the storybook to their own real life, learn to perceive their emotions, correctly deal with negative emotions, and eventually learn to regulate their emotions. The questions that can be discussed are: Will we encounter certain emotional problems in our lives in a certain way and solve them in a certain way (introducing the ways to solve emotional problems in the picture book story)? What are the benefits of this solution? When you encounter such a problem again in life, how do you solve it? After encountering the same problem in the future, will you try to solve the problem like the protagonist in the story?

\section{Let Infants Express Themselves with Pictures}

Because the language system of the child is not well developed, singing, dancing, and painting become the ways in which children express themselves. Especially for painting, like painting is the nature of young children. We can observe that young children can use anything as a canvas or brush to paint, such as the walls and floors of homes, use anything that can draw traces to be a brush, and paint everywhere. The study of art educators found that from the children's paintings, not only the approximate age of a child can be analyzed and judged, but also the development level of the child, for example, the development of his small muscles from his lines. Painting is also the child's first language, so you can try to let children express their emotions with paintings.

\section{Adjust Infants' Emotions through Picture Book Stories}

Infants are active. Just letting them perceive and understand emotions in a static manner will greatly reduce our effectiveness. Imagine a very sad and angry young child. We just let him listen to our story rather than allow him to express in his own emotions, can he find a solution to his emotional problems? Certainly not. Therefore, every time we read the emotion picture book, we must have the infant experience it firsthand, and the performance just gives us such an experience. In the storytelling performances, teachers must create a suitable situation in which children use their own body language to express their emotions, gradually imitate the strategies of the protagonist in solving the emotional problems, and feel and understand the emotional themes contained in the emotional picture books so as to promote the social development of children.

\section{Conclusion}

Childhood is an important period for the individual's life to lay a foundation for emotional development. It plays a leading role in the subsequent development of personality, cognitive ability, and social development. Therefore, it is necessary to carry out a series of emotional education themed activities for children in childhood to promote the development of children's emotional management ability. The cultivation of emotional management ability is a long-term process. It cannot be cultivated with one or two thematic activities. Nor is it a unilateral aspect of the teacher. It also requires the close cooperation of parents. It is based on the picture book as a vehicle for the homeland education. Through parent-child readings by parents and children, and kindergarten teachers' emotional picture book theme activities, children's emotional and healthy development is promoted more efficiently. 


\section{References}

[1] Prepared by the Department of Basic Education of the Ministry of Education. Guide for the Learning and Development of Children Aged 3-6. 2012:2-5.

[2] Zhaolan Meng. Emotional Psychology [M]. Beijing: Peking University Press, 2005:45-70.

[3] Ting Zhang. An Action Research on Picture Books Promoting the Development of Children's Emotional Ability [D]. Chongqing: Master thesis of Southwest University. 2010:12-24. http://www.cnki.net/.

[4] Fang Zhang. An Action Research on Emotional Education of Small Class Children Using Emotional Thematic Picture Books as Carriers [D]. Guangxi Normal University Master Thesis. 2014:23-33. http://www.cnki.net/.

[5] [U.S.A] Molly Calvin/Figure. Sophie is Angry [M]. Hebei Education Press. 2009.

[6] Jingjing Chen. Parent-child Reading Picture Books: A Good Way for Children's Families to Carry out Emotional Education [J]. Science and education, 2012(65).

[7] Ting Liu. Studies on the Action of Emotional Theme Picture Book to Promote the Development of Infants' Emotional Ability [D]. Southwest University Master Thesis, 2010:28-55.http://www.cnki.net/.

[8] [Japanese] Written by Tadashi Matsui; Translated by Dizhao Liu. The Seed of Happiness Parent-Children Picture Book [M]. Twenty-first Century Press. 2013:16-142.

[9] Peng L, Shizhao N, Zheng W, Ziwei J, Jianwu Y, Zhongxiang Q, Wangmo P. Predicting durations of online collective actions based on Peaks' heights [J]. Communications in Nonlinear Science and Numerical Simulation. 2018, 55: 338-354.

[10] Yunyan Liu, Ting Liu, Tao Zhou. Using Emotional Theme-Picture Books to Carry out the Theoretical Basis and Teaching Model of Young Children's Emotional Education [J]. Preschool Education Research, 2011(200).

\section{Introduction to the Author}

Huiyu Guo, female, born in March 1972 in Weinan, Shaanxi Province, Vice Professor at Xi'an University Research Direction: Children's Literatures Postcode: 710065

Address: Middle Campus, Xi'an University, No.212, South Taibai Road, Xi'an, Shaanxi Province

Telephone: 13572808092E-mail:263279298@qq.com; ghuiyu72@126.com 